\title{
ROBUST STABILITY OF FRACTIONAL-ORDER LTI SYSTEMS WITH INDEPENDENT STRUCTURE OF ELLIPSOIDAL PARAMETRIC UNCERTAINTY
}

\author{
Radek Matušů, Bilal Şenol \& Vladimír Vašek
}
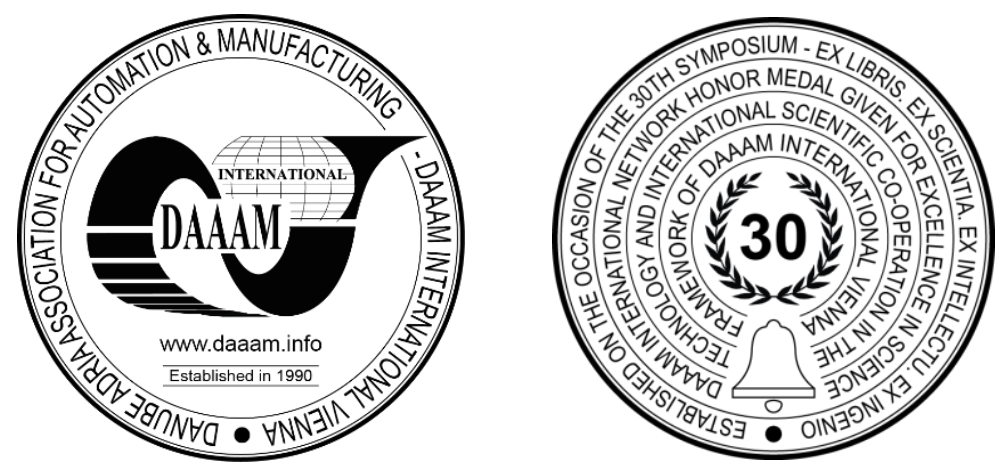

This Publication has to be referred as: Matusu, R[adek]; Senol, B[ilal] \& Vasek, V[ladimir] (2019). Robust Stability of Fractional-Order LTI Systems with Independent Structure of Ellipsoidal Parametric Uncertainty, Proceedings of the 30th DAAAM International Symposium, pp.0161-0166, B. Katalinic (Ed.), Published by DAAAM International, ISBN 978-3-902734-22-8, ISSN 1726-9679, Vienna, Austria

DOI: $10.2507 / 30$ th.daaam.proceedings.021

\begin{abstract}
This example-oriented contribution deals with the investigation of robust stability for fractional-order linear timeinvariant (LTI) systems with the independent structure of parametric uncertainty and ellipsoid-shaped uncertainty bounding set. Even though the ellipsoidal uncertainty is dependent by definition, its combination with the independent uncertainty structure is studied in this paper. The robust stability is tested via the application of the value set concept in combination with the zero exclusion condition. An example is elaborated for the family of fractional-order polynomials with a three-dimensional ellipsoidal uncertainty bounding set in order to demonstrate the effectivity of the applied graphical method.
\end{abstract}

Keywords: Robust Stability; Fractional-Order Systems; Ellipsoidal Uncertainty; Parametric Uncertainty; Independent Uncertainty Structure.

\section{Introduction}

Automatic control is an inseparable part of our daily life [1], [2], [3], and robust stability is one of the most fundamental requirements of practical control systems. It means that the stability must be guaranteed not only for one (nominal) system but also for a whole family of systems. Such families are assumed to represent some neighborhood of the nominal system. A natural approach to defining this neighborhood is known as the parametric uncertainty [4], [5], i.e., the system's structure is fixed, but the parameters are supposed to possibly "slowly" change within given bounds. The mostly utilized bound has a shape of a box, but there are other useful alternatives, such as a sphere or an ellipsoid [5], [6], [7], [8].

Fractional-order control systems become more and more popular nowadays [9], [10], [11] due to their superior performance compared to the classical integer-order circuits. Thus, the robust stability of fractional-order systems under various conditions of uncertainty is of great importance, as well [12], [13].

This contribution is intended to present the example of robust stability analysis for fractional-order linear timeinvariant (LTI) system with an independent structure of parametric uncertainty combined with an ellipsoid-shaped uncertainty bounding set. 
Notice that the ellipsoidal (or spherical as a special case) parametric uncertainty is actually always dependent by its definition, but the case of its combination with the independent uncertainty structure is analyzed in this contribution. The well-known tool for robust stability of integer-order systems with independent uncertainty structure and box-shaped uncertainty bounding set (i.e., interval polynomials) is the Kharitonov theorem. Then their spherical/ellipsoidal versions can be analyzed by means of the Soh-Berger-Dabke theorem [5], [14]. Unfortunately, these techniques are not directly applicable to fractional-order systems [12]. In this contribution, the robust stability is tested via the numerical calculation and subsequent plot of the value sets, and the application of the zero exclusion principle [5], [15], [16], [17].

\section{Ellipsoidal family of fractional-order polynomials with independent uncertainty structure}

Consider the family of fractional-order polynomials with the independent uncertainty structure:

$$
p(s, q)=s^{3.3}+q_{2} s^{2.1}+q_{1} s^{0.8}+q_{0}
$$

and with the uncertainty bounding set $Q$ :

$$
\begin{aligned}
& \left\|q-q^{0}\right\|_{2, W} \leq r=1 \\
& q^{0}=[1,2,3] \\
& W=\left[\begin{array}{ccc}
w_{0}^{2} & 0 & 0 \\
0 & w_{1}^{2} & 0 \\
0 & 0 & w_{2}^{2}
\end{array}\right]=\left[\begin{array}{lll}
4 & 0 & 0 \\
0 & 2 & 0 \\
0 & 0 & 1
\end{array}\right]
\end{aligned}
$$

i.e., equivalently:

$$
\begin{aligned}
& 4\left(q_{0}-q_{0}^{0}\right)^{2}+2\left(q_{1}-q_{1}^{0}\right)^{2}+\left(q_{2}-q_{2}^{0}\right)^{2} \leq r=1 \\
& q^{0}=[1,2,3]
\end{aligned}
$$

Obviously, this uncertainty bounding set constitutes a (three-dimensional) ellipsoid, which is shown in Fig. 1.

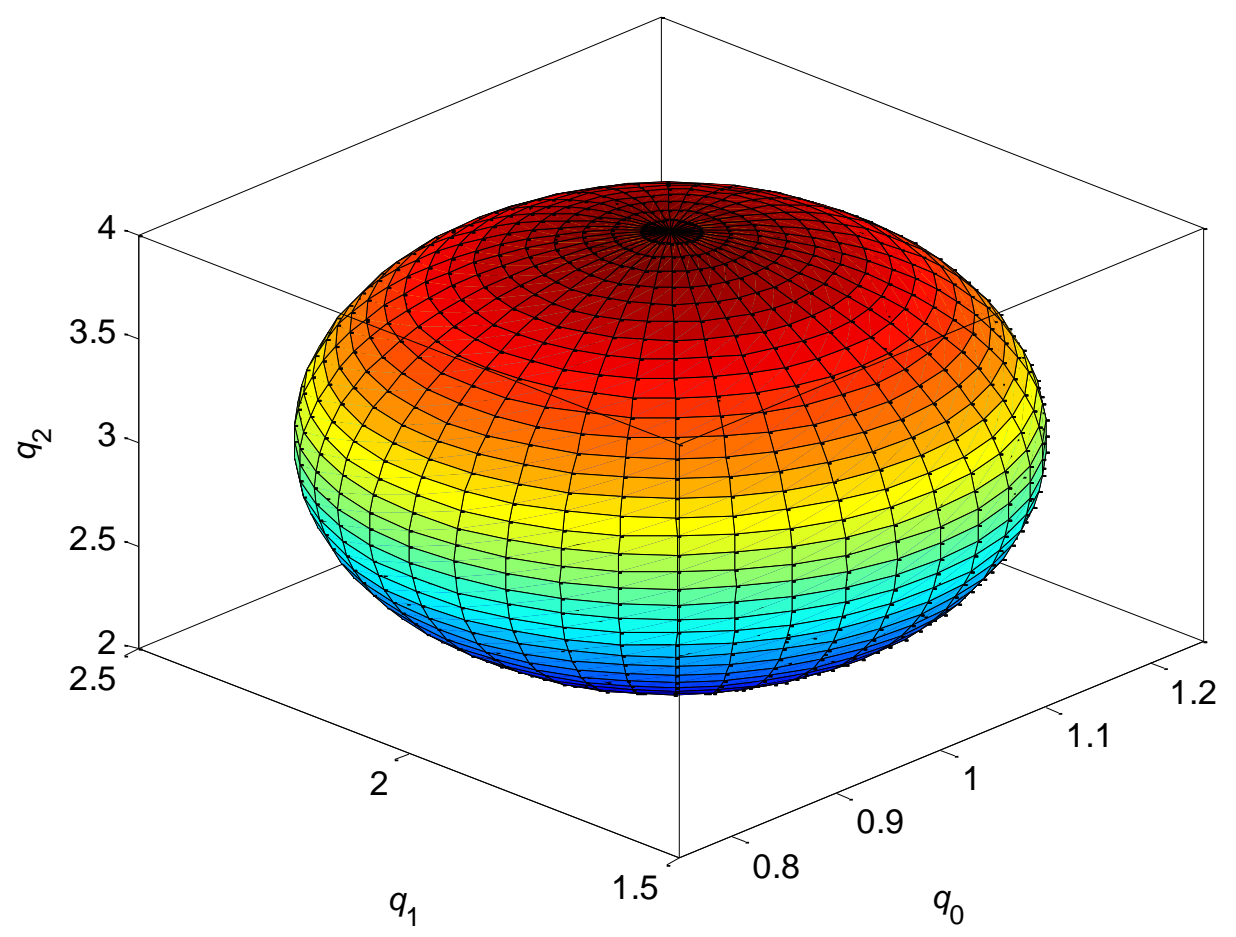

Fig. 1. Ellipsoidal uncertainty bounding set (2), (3) 


\section{Value-set-based robust stability analysis}

The value set $p(j \omega, Q)=\{p(j \omega, q): q \in Q\}$ [5] at frequency $\omega=2$ is depicted in Figs. 2-4. In this specific case with 3 uncertain parameters, it can be obtained through gridding the surface area of the ellipsoid and subsequent direct calculation of the related value set points. The surface area can be parameterized e.g. by means of the equations:

$$
\begin{aligned}
& q_{0}=\left(\frac{r}{w_{0}^{2}}\right) \cos \theta \cos \varphi+q_{0}^{0} \\
& q_{1}=\left(\frac{r}{w_{1}^{2}}\right) \cos \theta \sin \varphi+q_{1}^{0} \\
& q_{2}=\left(\frac{r}{w_{2}^{2}}\right) \sin \theta+q_{2}^{0}
\end{aligned}
$$

where $\theta \in[0,2 \pi]$ and $\varphi \in[0, \pi]$.

Sampling both parameters $\theta$ and $\varphi$ by 30 equidistant samples within the intervals mentioned above leads to the "sparse" value set (Fig. 2), sampling each parameter by 100 samples makes the value set more "dense" (Fig. 3), and finally, sampling by 300 samples produces the value set that represents almost continuous area visually (Fig. 4). Anyway, it can be clearly seen that the boundary of the uncertainty bounding set (the ellipsoid surface area from Fig. 1) is mapped not only to the boundary of the value set but also into the interior of the value set (Figs. 2-4). On the other hand, the boundary of the value set is mapped only from the boundary of the uncertainty bounding set, i.e., no internal point from the ellipsoid in Fig. 1 can be mapped to the boundary of the value set in Figs. 2-4). However, this holds true only for simple uncertainty structures (such as independent one, which is studied in this contribution, and affine linear one), not for more complicated ones [5], [15], [16], [17].

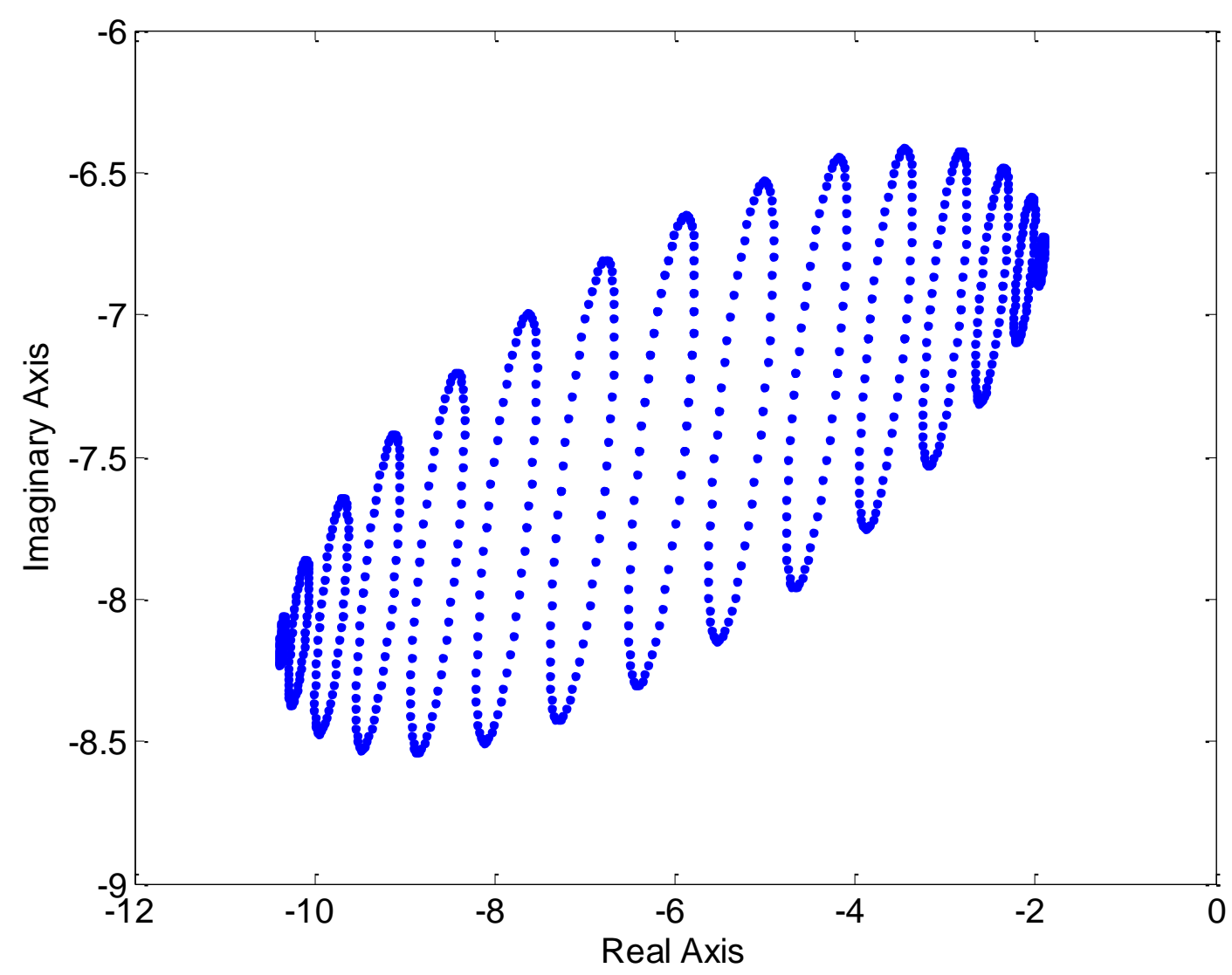

Fig. 2. Value set of (1), (2) for $\omega=2$ and 30 samples of $\theta$ and $\varphi$ 


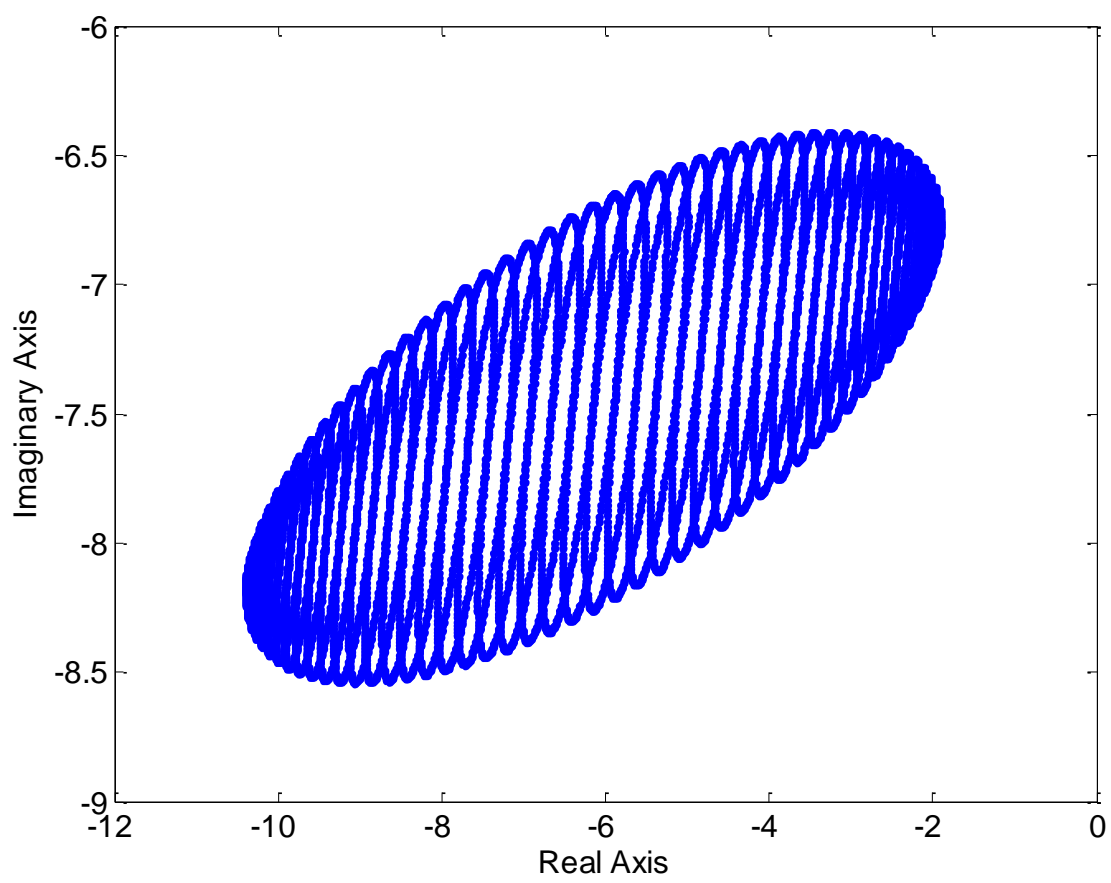

Fig. 3. Value set of (1), (2) for $\omega=2$ and 100 samples of $\theta$ and $\varphi$

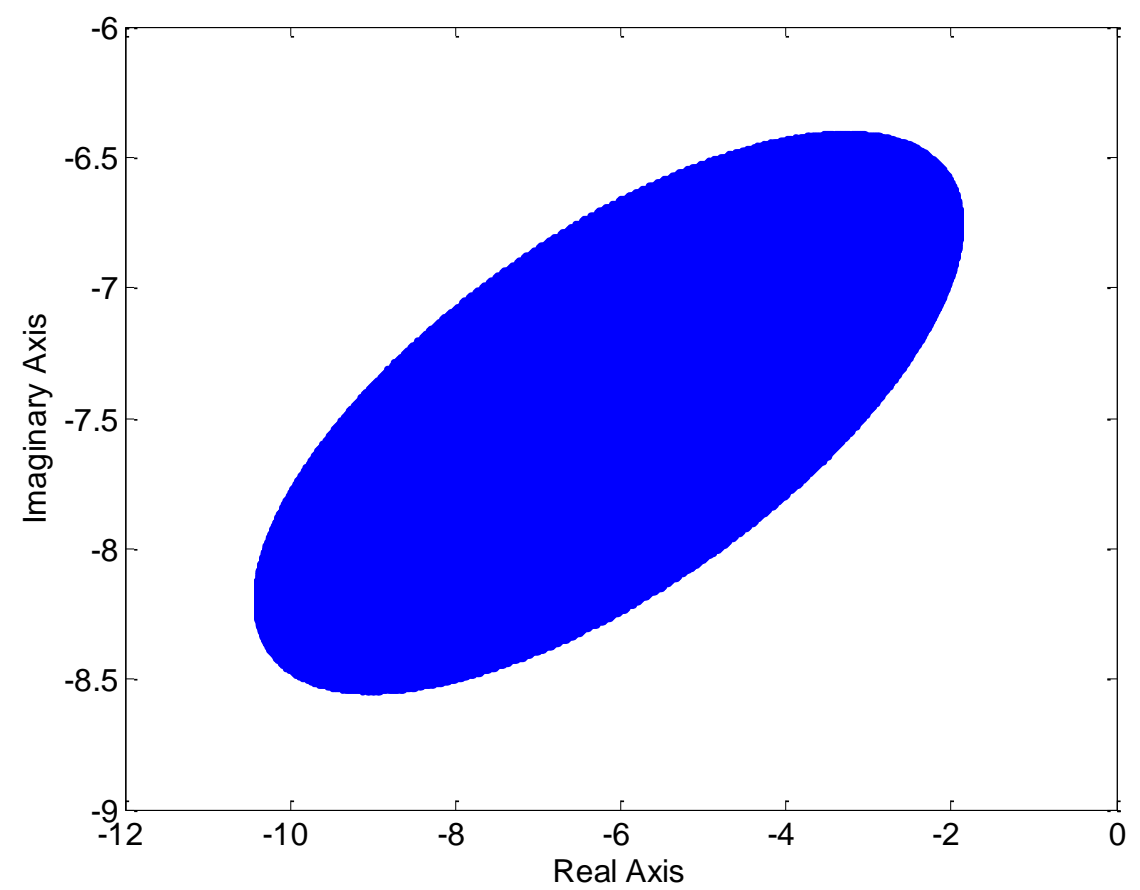

Fig. 4. Value set of (1), (2) for $\omega=2$ and 300 samples of $\theta$ and $\varphi$

The value sets for the range of frequencies from 0 to 2 with step 0.1 are shown in Fig. 5. They would also enter the fourth quadrant for even higher values of $\omega$. According to the zero exclusion condition [5], [17], the family of FO polynomials (1), (2) is robustly stable since the zero (complex plane origin) is excluded from the value sets and all necessary preconditions (invariant degree of the polynomial family, pathwise connected $Q$, continuous coefficient functions, and at least one stable member of the family) are fulfilled. 


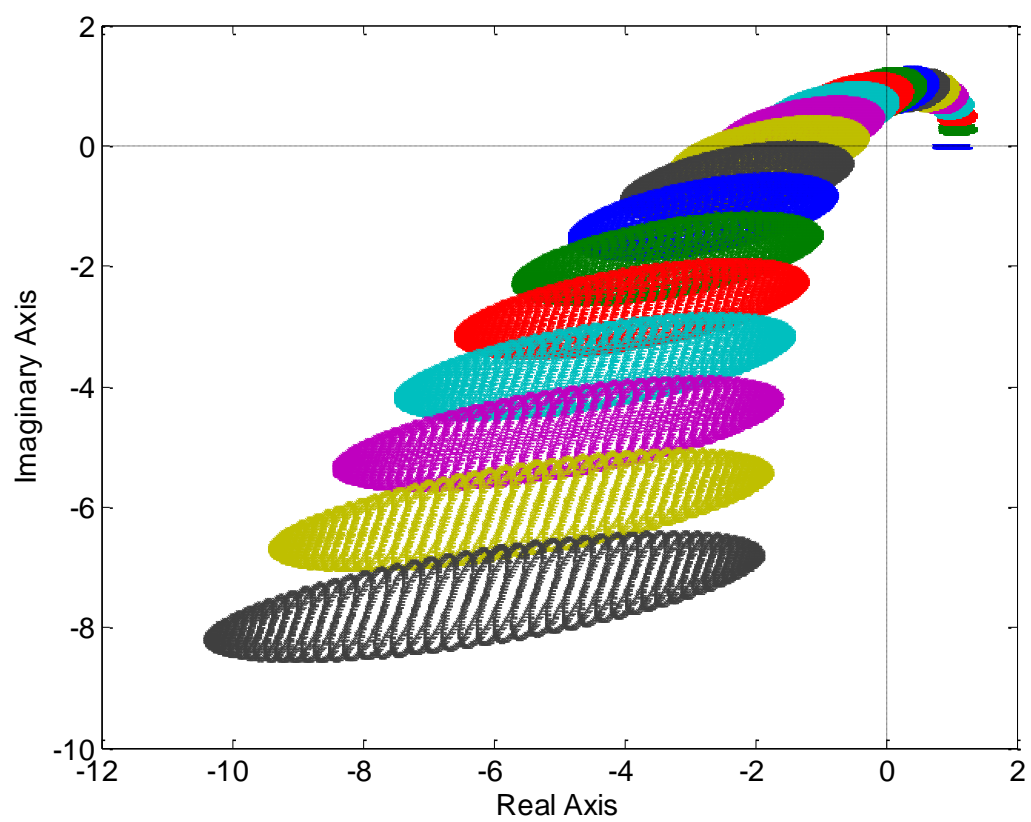

Fig. 5. Value sets of (1), (2) for $\omega=0: 0.1: 2$

\section{Conclusion}

The contribution was focused on presenting a brief example that illustrated the value-set-based method for testing the robust stability of the fractional-order LTI system with an independent structure of parametric uncertainty and an ellipsoid-shaped uncertainty bounding set. As could have been seen, the technique is straightforward, relatively easy-touse, and tests the robust stability with necessary and sufficient condition. Contrarily, it suffers a considerable computational burden, especially if it is generalized for systems with higher dimensions of uncertainty bounding set and if a dense sampling is requested.

\section{Acknowledgments}

This work was supported by the Ministry of Education, Youth and Sports of the Czech Republic within the National Sustainability Programme project No. LO1303 (MSMT-7778/2014).

\section{References}

[1] Mitin, F. \& Krivushov, A. (2018). Application of Optimal Control Algorithm for DC Motor, Proceedings of the 29th DAAAM International Symposium, pp. 0762-0766, B. Katalinic (Ed.), Published by DAAAM International, ISBN 978-3-902734-20-4, ISSN 1726-9679, Vienna, Austria

[2] Klos, S.; Fedoryshyn, R.; Savytskyi, V.; Pistun, Y. \& Matiko, F. (2017). Classification of Automatic Controllers Diagrams, Proceedings of the 28th DAAAM International Symposium, pp. 0967-0973, B. Katalinic (Ed.), Published by DAAAM International, ISBN 978-3-902734-11-2, ISSN 1726-9679, Vienna, Austria

[3] Filaretov, V. F.; Konoplin, A.; Konoplin, N. \& Gorbachev, G. (2016). Control System for Underwater Vehicle With Multilink Manipulator for Automatic Manipulation Operations, Proceedings of the 27th DAAAM International Symposium, pp. 0714-0720, B. Katalinic (Ed.), Published by DAAAM International, ISBN 978-3-902734-08-2, ISSN 1726-9679, Vienna, Austria

[4] Bhattacharyya, S. P. (2017). Robust control under parametric uncertainty: An overview and recent results. Annual Reviews in Control, Vol. 44, pp. 45-77

[5] Barmish, B. R. (1994). New Tools for Robustness of Linear Systems, Macmillan, New York, USA

[6] Sadeghzadeh, A. (2012). Identification and robust control for systems with ellipsoidal parametric uncertainty by convex optimization. Asian Journal of Control, Vol. 14, No. 5, pp. 1251-1261

[7] Sadeghzadeh, A.; Momeni, H. \& Karimi, A. (2011). Fixed-order Hœ controller design for systems with ellipsoidal parametric uncertainty. International Journal of Control, Vol. 84, No. 1, pp. 57-65

[8] Matušů, R. (2016). Spherical Families of Polynomials: A Graphical Approach to Robust Stability Analysis. International Journal of Circuits, Systems and Signal Processing, Vol. 10, pp. 326-332

[9] Machado, J. A. T.; Kiryakova, V. \& Mainardi, F. (2011). Recent history of fractional calculus. Communications in Nonlinear Science and Numerical Simulation, Vol. 16, No. 3, pp. 1140-1153 
[10] Chen, Y.; Petráš, I. \& Xue, D. (2009). Fractional Order Control - A Tutorial, Proceedings of the 2009 American Control Conference, St. Louis, MO, USA

[11] Xue, D. (2017). Fractional-Order Control Systems: Fundamentals and Numerical Implementations, De Gruyter, Berlin, Germany

[12] Tan, N.; Özgüven, Ö. F. \& Özyetkin, M. M. (2009). Robust stability analysis of fractional order interval polynomials. ISA Transactions, Vol. 48, No. 2, pp. 166-172.

[13] Jiao, Z. \& Zhong, Y. (2012). Robust stability for fractional-order systems with structured and unstructured uncertainties. Computers \& Mathematics with Applications, Vol. 64, No. 10, pp. 3258-3266

[14] Soh, C. B.; Berger, C. S. \& Dabke, K. P. (1985). On the stability properties of polynomials with perturbed coefficients. IEEE Transactions on Automatic Control, Vol. 30, No. 10, pp. 1033-1036

[15] Matušů R. (2019): Value Sets of Ellipsoidal Polynomial Families with Affine Linear Uncertainty Structure. In: Cybernetics and Automation Control Theory Methods in Intelligent Algorithms: Proceedings of the 8th Computer Science On-line Conference 2019, Vol. 3 - Advances in Intelligent Systems and Computing (Vol. 986), Silhavy, R. (Ed.), pp. 255-263. Springer Nature Switzerland AG, Cham, Switzerland

[16] Matušů, R. \& Şenol, B. (2019). Application of Value Set Concept to Ellipsoidal Polynomial Families with Multilinear Uncertainty Structure. In: Computational Statistics and Mathematical Modeling Methods in Intelligent Systems: Proceedings of 3rd Computational Methods in Systems and Software 2019, Vol. 2 - Advances in Intelligent Systems and Computing (Vol. 1047), Silhavy, R., Silhavy P., Prokopova Z. (Eds.), pp. 81-89. Springer Nature Switzerland AG, Cham, Switzerland

[17] Matušů, R. \& Şenol, B. (2019). Value-Set-Based Approach to Robust Stability Analysis for Ellipsoidal Families of Fractional-Order Polynomials with Complicated Uncertainty Structure, unpublished manuscript 